\title{
The Economics of Infectious Disease, Trade and Pandemic Risk
}

The emergence and spread of zoonotic diseases has long been recognized as an incidental effect of our species' activities on the planet-especially production and trade. The emergence of zoonoses results from activities that bring susceptible people into contact with livestock and wild animals infected with novel pathogens-whether bacteria, parasites, fungi, viruses or prions. Spread results from activities that move infected individuals, or that alter the range of wild reservoirs or vectors. Neither process is new. Diseases such as plague, yellow fever, influenza, anthrax and tuberculosis all originally emerged through contact with infected wild reservoirs. The spread of smallpox, typhus, and measles from Europe to the USA in the century after Columbus's first voyage across the Atlantic was an incidental effect of voyages of exploration and exploitation.

What is new is the rate at which novel diseases are emerging, and the speed with which they are spread. Severe acute respiratory syndrome (SARS), Middle East respiratory syndrome (MERS), Hendra virus $(\mathrm{HeV})$, and Nipah virus (NiV) represent a host of zoonotic diseases first identified only in the last 25 years-a product of population-driven pressure on the world's remaining wildlife refugia. The rate by which emerging diseases spread is also accelerating, as a by-product of the growth of trade and travel across increasingly tightly linked networks. Once SARS arrived in Hong Kong from Guangdong Province in China in February 2003 , it was spread to multiple countries in a matter of days. The global air traffic network now has the capacity to move pathogens worldwide in a matter of hours.

While there is good reason to believe that rates of emergence and spread will eventually saturate as pathogens become increasingly widely distributed, this will not hap- pen any time soon. Two recent studies identified novel viruses from large sample set of two zoonotic disease reservoirs (a fruit bat and a macaque) and then used markrecapture algorithms to estimate their unknown viral diversity. Extrapolation to all terrestrial mammals and water birds indicates that around 1.6 million unknown viruses exist within viral families known to contain zoonoses in these host groups. This implies that there may be between 650,000 and 840,000 unknown zoonoses waiting to emerge (Carroll et al. 2018).

The current trends pose challenges for both the science and management of infectious disease. From a scientific perspective, the problem is to generate predictive models that capture the interactive effects of the epidemiological, ecological, and socioeconomic processes at work in emergence and spread. There is scope for strengthening existing models of both. Emergence risks tend to be highest in tropical regions where population-driven expansion into wildlife refugia brings susceptible people or livestock into contact with wildlife reservoirs of diseases new to humankind (Jones et al. 2008). By combining efforts to model diseases-in-waiting, the process of land use change and its effects on population densities in wildlife refugia, and exposure at the margins of converted land, it is possible to estimate differences in the disease risks posed by similar processes in different parts of the world. Spread risks, by contrast, tend to be highest in regions most tightly connected by trade and travel (Tatem et al. 2006a, b). By combining efforts to model the epidemiological processes involved, trade and travel networks, changes in trade and travel volumes, and biosecurity along trade/travel routes, it is possible to estimate differences in the disease risks faced by people in different parts of the world. 
For both emergence and spread, risk is a product of decisions made by people, and hence of the conditions that lie behind those decisions. Factoring the decision process into models of emergence and spread not only improves the predictive power of those models, but adds to the instruments available to disease managers (Perrings et al. 2014). The papers included in this special feature focus on two issues. One is prediction of the course of disease once an outbreak has occurred. A second is the role of private decisions that either increase or decrease disease risk.

The special feature focuses on the effect of a decisionenvironment that comprises both a public health/biosecurity regime and the economic factors that drive risky activities. The private decision to convert land at the edges of wildlife refugia may, for example, be driven by relative land prices, property rights and land access regimes, alternative employment opportunities, agricultural product markets and so on. The private decision to import risk materials similarly reflects relative product prices, shipping costs, exchange rates and the like. In all such cases, the risk to society depends on a private calculus - whether the private benefits of a risky activity outweigh the private costs.

The volume and direction of trade are generally good empirical predictors of the sources of epizootic and zoonotic diseases (Pavlin et al. 2009; Smith et al. 2009), but this is conditioned by the effectiveness of the public health/ biosecurity regime in place. Biosecurity measures do not always identify the source of risk. A ban on Russian pigs and pig products caused by the presence of African swine flu in Russia, for example, failed to remove the risk posed by infected containers or trade vehicles that were not targeted (Mur et al. 2012). Nonetheless, differences in biosecurity measures on different trade routes do matter. The growth of trade with emerging markets and developing economies, for example, has increased the likelihood of reinfection from existing reservoirs (Di Nardo et al. 2011).

Getting the science of infectious disease right implies a better understanding of the epidemiological consequences of trading decisions: the importer's decision about what to trade with whom, the traveller's decision about where to go and when. Among disease managers, there is current concern that existing risk assessments and the risk management strategies they inform fail to capture the true risks of trade. In some instances the neglect of trade means that risks are underestimated (Barker et al. 2006; King et al. 2006). In others, the risks of either particular diseases or particular commodities may be overestimated (Bruckner 2011; MacDiarmid 2011).
Improving the management of infectious disease implies a better appreciation of the potential for influencing risk by altering not just the biosecurity regime but also the costs and benefits facing both traders and travellers. Where the risks faced by society are an externality of private decisions, they can be mitigated by altering the private net benefits of those decisions. Traders and travellers can be confronted with the cost of their actions. In the limit, these could include the expected cost of pandemics such as SARS, Foot and Mouth Disease, or Highly Pathogenic Avian Influenza. Strengthening the science of infectious disease to include the factors behind risky decisions may provide health authorities with a valuable set of tools with which to contain risk. Charging traders with the expected cost of their actions could generate valuable resources to respond when emerging or re-emerging disease outbreaks occur.

\section{Charles Perrings}

School of Life Sciences,

Arizona State University, Tempe, USA

e-mail: Charles.Perrings@asu.edu

Simon Levin

Department of Ecology and Evolutionary Biology,

Princeton University, Princeton, USA

Peter Daszak

EcoHealth Alliance, New York, USA

\section{REFERENCES}

Barker I, Brownlie J, Peckham C, Pickett J, Stewart W, Waage J, et al. (2006) Foresight: Infectious Diseases-Preparing for the Future, London: Office of Science and Innovation

Bruckner GK (2011) Managing the risks of disease transmission through trade: a commodities-based approach? Scientific and Technical Review International Office of Epizootics 30:289-296

Carroll D, Daszak P, Wolfe ND, Gao GF, Morel CM, Morzaria S, et al. (2018) The Global Virome Project. Science 359:872-874

Di Nardo A, Knowles NJ, Paton DJ (2011) Combining livestock trade patterns with phylogenetics to help understand the spread of foot and mouth disease in sub-Saharan Africa, the Middle East and Southeast Asia. Scientific and Technical Review International Office of Epizootics 30:63-85

Jones KE, Patel N, Levy M, Storeygard A, Balk D, Gittleman JL, et al. (2008) Global trends in emerging infectious diseases. Nature 451:990-993

King DA, Peckham C, Waage JK, Brownlie J, Woolhouse MEJ (2006) Infectious diseases: Preparing for the future. Science 313:1392-1393 
MacDiarmid TR (2011) The spread of pathogens through international trade. Scientific and Technical Review International Office of Epizootics 30:13-17

Mur L, Martinez-Lopez B, Sanchez-Vizcaino JM (2012) Risk of African swine fever introduction into the European Union through transport-associated routes: returning trucks and waste from international ships and planes. BMC Vet Res 8:149

Pavlin B, Schloegel LM, Daszak P (2009) Risk of Importing Zoonotic Diseases through Wildlife Trade, United States. Emerging Infectious Disease 15:1721-1726

Perrings C, Castillo-Chavez C, Chowell G, Daszak P, Fenichel E, Finnoff D, et al. (2014) Merging Economics and Epidemiology to Improve the Prediction and Management of Infectious Disease. Ecohealth 11:464-475

Smith KF, Behrens M, Schloegel LM, Marano N, Burgiel S, Daszak P (2009) Reducing the Risks of the Wildlife Trade. Science 324:594-595

Tatem AJ, Hay SS, Rogers DJ (2006) Global traffic and disease vector dispersal. Proceedings of the National Academy of Sciences 103:6242-6247

Tatem AJ, Rogers DJ, Hay SI (2006) Global transport networks and infectious disease spread. Advances in Parasitology 62:293-343

Published online: July 12, 2018 